\title{
A study on comfort properties of oak Tasar silk waste and acrylic blended fabrics
}

\author{
Pallavi Lakhchaura* \\ Department of Home Science, Faculty of Arts, Dayalbagh Educational Institute, Dayalbagh, \\ Agra-282005 (Uttar Pradesh), India \\ Manisha Gahlot \\ Department of Clothing and Textiles, College of Home Science, G. B. Pant University of \\ Agriculture and Technology, Pantnagar-263145 (Uttarakhand), India \\ *Corresponding author. Email: pallavi.lakhchaura@gmail.com
}

\section{How to Cite}

Lakhchaura, P. and Gahlot, M. (2021). A study on comfort properties of oak Tasar silk waste and acrylic blended fabrics. Journal of Applied and Natural Science, 13(2), 476 - 481. https://doi.org/10.31018/jans.v13i2.2631

\begin{abstract}
Oak Tasar is wild silk with natural golden brown colour and unique texture available in Himalayan region of India. A lot of fibre waste is generated during hand spinning of oak Tasar silk yarn which can be utilized by blending it with compatible fibre to incorporate the properties of both fibres in the yarn. The present study aimed to develop Oak Tasar silk waste and acrylic blended fabrics and study their comfort properties. The oak Tasar silk and acrylic blended plain weave and twill weave fabrics were prepared with five different blend ratios viz. 100:0, 60:40, 50:50, 40:60 and 0:100. The prepared fabrics were studied for comfort properties like thermal insulation (clo, TIV \%), Q-max (warm/cool feeling), air permeability, water vapour transport rate and were statistically analysed. Results revealed that thermal insulation and clo value were found to be increased with increasing acrylic content in the fabric whereas Q- max, air permeability, water vapour permeability values were reduced with the addition of oak Tasar silk fiber in the blend. The 50:50 blended plain weave fabric among the blended fabrics had the highest clo value, i.e. 0.52 and 50:50 blended twill weave fabric had highest $Q$ max value i.e. $0.109 \mathrm{~W} / \mathrm{cm}^{2}$. It was found from the study that the developed fabrics are comfortable and can be used for light winters.
\end{abstract}

Keywords: Acrylic blended fabrics, Oak Tasar, Comfort, Silk waste, Thermal insulation

\section{INTRODUCTION}

Comfort is the utmost aspect of clothing which is needed foremost by the wearer. Comfort is a perception of well-being in which the human body is in psychological, physiological and physical harmony with the environment where it is situated (Raeve et al., 2018). It is contributed by various factors like garment fit, persons' physiological need, psychological need, fabric construction, yarn construction and fibre properties. Clothing properties are very important for human thermal comfort (Valsang and Patil, 2013). The body produces lots of heat energy and the body temperature increases. To reduce the high temperature, the body perspires a lot in liquid and vapour form. While this perspiration is transmitted to the atmosphere, the body temperature reduces and then the body feels cool. So the garments should allow the perspiration to pass through, otherwise, it will result in discomfort (Raeve et al. 2018).
Thermal insulation is one the property which is required in winter wear fabric. The fabric's thermal insulation is affected by the fibre properties and the yarn and fabric properties. Fibres such as few natural and synthetic fibres are considered good as winter wear material due to their warmth properties. Synthetic fibers are crimped to increase the amount of air space within the fabric. The crimp prevents the fiber packing tightly in the fabric and so creates pockets of air. Many fabric structures can trap still pockets of air and act as insulators under still air conditions (Narkhedkar and Vora, 2017).

Oak Tasar silk is one of the wild silk types obtained from Antherea proyeli found in the Himalayan region. It has its natural brown colour and luxurious texture along with its good moisture absorption. Silk is the natural fibre that has versatile use both in summers and winters too. Acrylic is one of the fibre which is known for its warmth without weight property but hydrophobic in nature. Blending is one of the methods to combine the 
good properties of both the fibres to produce a desirable yarn with the unique colour and texture of Tasar silk. The present study aimed to develop and study the comfort properties of oak Tasar silk waste and acrylic blended fabric used in light winters.

\section{MATERIALS AND METHODS}

Three oak Tasar silk and acrylic blended yarns were developed with 60:40, 50:50 and 40:60 blend ratios and the pure yarns of oak Tasar silk and acrylic fibres at Northern India Textile Research Assosiation Ghaziabad on ring spinning system. Oak Tasar silk waste fibre was procured from Appropriate Technology India, Dehradun, Uttarakhand and acrylic fibres were procured from Pasupathi spinning mill Kashipur, Uttarakhand. The yarn counts of the developed yarns were in the range from $25 \mathrm{Ne}$ to $28 \mathrm{Ne}$. Ten fabric samples were woven from developed yarns on the handloom, out of which four were blended fabrics with plain weave and four with twill weave. Two were union fabrics, each with plain and twill weave in which $100 \%$ acrylic yarn was used as warp and 100 $\%$ oak Tasar silk yarn was used as weft. The comfort (thermal insulation value, clo, Q-max, air permeability, water vapour transport rate, water absorption, vertical wicking and horizontal wicking) properties were assessed and statistically analyzed using post hoc tukey test and paired t- test.

\section{Q-max}

The test for Q-max was conducted at Textile Testing Lab, CIRCOT, Mumbai. The instrument used for measuring Q-max was Kawabata Evaluation System-F7 THERMO LABO II. The size of the sample taken was $20 \mathrm{~cm} \times 20 \mathrm{~cm}$ (actual measured area was $5 \mathrm{~cm} \times 5 \mathrm{~cm}$ ) under the standard conditions in $20 \pm 2^{\circ} \mathrm{C}$ and relative humidity $65 \pm 2 \% \mathrm{RH}$ for 24 hours. KES-F7 THERMO LABO II was switched on and kept for warming up for 15 minutes, then heater of heat flat was turned on and temperature-box was set to $35 \pm 0.1^{\circ} \mathrm{C}$ after that guard heater was turned on. The temperature of the water box was set at $25^{\circ} \mathrm{C}$ and fabric sample was placed above water box and Q-max button was turned on. When temperature-box reached $35^{\circ} \mathrm{C}$, it was moved and placed over the test sample and kept vertical, and then readings of $Q$ - max were recorded on the monitor. It was expressed in watt per square centimetre $(\mathrm{W} / \mathrm{cm} 2)$. Three readings were noted and their average was calculated.

\section{Thermal insulation (KES- F7)}

Thermal insulation is denoted by clo value and thermal insulation value (\%). The test for thermal insulation was conducted at Textile Testing Lab, CIRCOT, Mumbai. The instrument used for measuring thermal insulation was Kawabata Evaluation System-F7 THERMO LABO II. The readings were measured for all the blended and union fabrics. Three readings were taken for each sample and their mean values were taken.

\section{Air permeability (IS: 11056-1984)}

The air permeability of fabric is a measure of how well it allows the passage of air through it. Air permeability is defined as the volume of air in millimetres which is passed in one second through $100 \mathrm{~mm} 2$ of the fabric at a pressure difference of $10 \mathrm{~mm}$ head of water (Saville, 2004). Circular specimen of size $10 \mathrm{~cm}$ diameter was taken. The specimen was clamped over the air inlet of the apparatus using rubber gaskets and the air was sucked through it by means of a pump. The air valve was adjusted to give a pressure drop across the fabric of $10 \mathrm{~mm}$ water column and the rotometer readings were noted from the instrument. Five rotometer readings were taken with test area of $508 \mathrm{~mm} 2(25.4 \mathrm{~mm}$ diameter) for each woven sample and their mean was taken. The air permeability of each sample was calculated in $(\mathrm{cc} / \mathrm{sec} / \mathrm{cm} 2)$ given by

Air permeability $(R)=r \times 1000 / 60 \times 60 \mathrm{~A}$ .Eq. 1 Where, $r=$ Rotometer reading in litre per hour $A=5.08 \mathrm{~cm}^{2}$

\section{Water vapour permeability (ASTM E96-00)}

The dish method was used to measure the water vapour transport rate. The test for water vapour transport rate was conducted at testing lab of CIRCOT Mumbai. The specimen under test was sealed over the open mouth of a dish containing water and was placed at temperature $25^{\circ} \mathrm{C}$ and $65 \%$ relative humidity. Each dish was filled with sufficient distilled water so that a 10 $\mathrm{mm}$ air gap was maintained between the water surface and the fabric. Wire support was placed on each dish to keep the fabric level. Contact adhesive was applied to the rim of the dish and specimen, 96 $\mathrm{mm}$ in diameter. The cover ring was then placed over the dish and the gap between the cover ring and dish was sealed with PVC tape. All the dishes were then placed in the standard atmosphere and left for $1 \mathrm{hr}$ to establish equilibrium. Each dish was then weighed and time was noted. After $24 \mathrm{hrs}$, the dishes were reweighed and the time was noted again. Three readings were noted and their mean values were taken. The value of water vapour transportation rate (WVTR) was calculated as per the formula given by Saville (2004)

WVTR $=24 \mathrm{M} / \mathrm{At} \mathrm{g} / \mathrm{m}^{2} / \mathrm{day}$ .......Eq.2

Where, $M=$ loss in mass $(\mathrm{g})$

$\mathrm{t}=$ time between weighing $(\mathrm{hr})$

$A=$ internal area of dish $\left(\mathrm{m}^{2}\right)$

$A=\pi d 2 \times 10-6$

4

Where $\mathrm{d}=$ internal diameter of dish $(\mathrm{mm})$ 
Lakhchaura, P. and Gahlot, M. / J. Appl. \& Nat. Sci. 13(2), 476 - 481 (2021)

\section{RESULTS AND DISCUSSION}

\section{Comfort properties of developed blended and union fabric}

The comfort properties are concerned with heat and moisture transport properties of fabric. The test carried out for comfort properties were thermal insulation (clo, TIV \%), Q-max (warm/cool feeling), air permeability, water vapour transport rate.

\section{Thermal insulation}

Table1 depicts the clo values and thermal insulation values (TIV \%) of both plain and twill weave fabrics for all blend proportions.

In case of plain weave sample, $100 \%$ acrylic fabric had highest $(0.53)$ clo value followed by $50: 50$ blend ratio (0.52), 40:60 blend ratio (0.50), union and 60:40 blend ratio (0.47). Statistically, clo values of union, $60: 40$ blend and 40:60 blend showed no significant difference with each other at $5 \%$ significance level. A significant difference $(p<0.05)$ was observed between $100 \%$ acrylic and 60:40 blended plain weave fabric. Among twill fabrics, highest $(0.63)$ clo value was obtained for $100 \%$ acrylic fabric followed by acrylic/Tasar union (0.53 clo), $60: 40$ blend (0.52 clo), $50: 50$ blend $(0.5 \mathrm{clo}$ ) and $40: 60$ blend $(0.51 \mathrm{clo})$. The clo value of $100 \%$ acrylic twill fabric had a significant difference with the values of all other blended ratios at $5 \%$ significance level. However, the clo values of all other oak Tasar: acrylic blended fabrics showed no significant difference ( $p>0.05$ ).

The highest thermal insulation value (TIV \%) among plain weave fabrics was found for $100 \%$ acrylic fabric (30.9\%) followed by 50:50 (29.6\%), 40:60 (26.6\%), acrylic/Tasar union (26.6\%) and least for 60:40 (21.6 $\%$ ) blend ratio. In case of twill weave highest TIV \% was found also for $100 \%$ (42.1\%) acrylic fabric followed by acrylic/Tasar union (31.2\%), 60:40 (29.4\%), $50: 50(28.2 \%)$ and $40: 60(27.7 \%)$ blend ratios. Statistical analysis of TIV \% of plain weave fabrics showed that a $0: 100$ blend ratio had significant difference $(p<0.05)$ with acrylic/Tasar union and 60:40 blend ratio. No significant difference was found among TIV \% of 0:100, 50:50 and 40:60 blend ratios at $5 \%$ significance level. Statistical analysis TIV \% of twill weave fabrics showed that TIV \% of union, 60:40, 50:50 and 40:60 blended fabrics had no significant difference at $5 \%$ level of significance.

It was observed from the data that twill fabrics had higher clo value and TIV \% than plain weave fabrics for $0: 100$, union, $60: 40$ and $40: 60$ blended fabrics. For both plain and twill weaves, $100 \%$ acrylic fabric had the highest clo value and thermal insulation values. It can be observed from data that TIV \% and clo values decreased for both plain and twill weave fabrics with the addition of oak Tasar fibres with acrylic fibres as com- pared to $100 \%$ acrylic fabric. This might be due to high moisture content of oak Tasar silk fibre compared to acrylic fibre. These observations were in accordance with the study of Shekar et al. (2001) the loss in insulation was proportional to fibre moisture content. According to Song (2011) the clo value of women's long sweater and men's jacket was in the range of 0.37 to 0.49 clo. Ghosh et al. (2016) studied the thermal insulation properties of jute and polyester fibre blended nonwoven fabrics. It was observed that the thermal insulation value (clo) showed decreasing trend with increased jute content in the blend, which was due to the higher moisture content of jute fibre compared to polyester.

\section{Q-max}

The data relating to Q-max (warm/cool feeling) of both plain and twill weave fabrics is given in Table 2. It can be seen from the Table 2 that in case of plain weave, $0: 100$ blend ratio had highest value $\left(0.104 \mathrm{~W} / \mathrm{cm}^{2}\right)$ of Q-max followed by $60: 40\left(0.102 \mathrm{~W} / \mathrm{cm}^{2}\right), 40: 60(0.100$ $\left.\mathrm{W} / \mathrm{cm}^{2}\right), 50: 50\left(0.101 \mathrm{~W} / \mathrm{cm}^{2}\right)$ blend ratios and acrylic/ Tasar union $\left(0.097 \mathrm{~W} / \mathrm{cm}^{2}\right)$ fabric. But statistically, Qmax values of $0: 100$ and $60: 40$ were at par at $5 \%$ significance level. Similarly, Q-max values of union fabric, $50: 50$ and 40:60 were at par $(p>0.05)$. However, $Q-$ max value of $60: 40$ blend was found to be significantly different $(p<0.05)$ from the union, $50: 50$ and $40: 60$ blend. Likewise, the Q-max value of 0:100 blend was significantly different from union, 50:50 and 40:60 blend.

In case of twill weave, 50:50 blend exhibited highest $\left(0.109 \mathrm{~W} / \mathrm{cm}^{2}\right) \mathrm{Q}$-max value. The least value $(0.97 \mathrm{~W} /$ $\mathrm{cm}^{2}$ ) was obtained for 40:60 blend. The Q-max values of $60: 40$ blend, $0: 100$ blend and union fabric were $0.103 \mathrm{~W} / \mathrm{cm}^{2}, 0.103 \mathrm{~W} / \mathrm{cm}^{2}$ and $0.101 \mathrm{~W} / \mathrm{cm}^{2}$ respectively. Statistically, Q-max values of 0:100 blend, union and 60:40 were at par at $5 \%$ significance level. Similarly, Q-max values of union and 40:60 had no significant difference. However, Q-max value of 0:100 blend had significant difference with 50:50 blend and 40:60 blend. Likewise, $60: 40$ blend had significant difference with $50: 50$ blend and 40:60 blend.

The larger the Q-max value, the cooler the feeling and the smaller the Q-max value, the warmer the feeling. The fabric contact area is the most important determinant of how warn and cool a fabric feels to an individual. The rough surface reduced the area of contact and smooth surface increased the area of contact (Anonymous, 2010). Chattopadhyay (2008) reported that yarn made of finer fibre will be compact and will hold less air in between the fibres intersections. As a result, the fabric was expected to be less warm.

Similar trend was observed in Q-max value of plain weave fabrics. The $100 \%$ acrylic plain weave fabric exhibited a cool feeling (Q-max $\left.=0.104 \mathrm{~W} / \mathrm{cm}^{2}\right)$ com- 
Table 1. Clo value and thermal insulation value (TIV \%) of woven fabrics.

\begin{tabular}{llllll}
\hline \multirow{2}{*}{ S.No. } & \multirow{2}{*}{ Types of fabrics } & \multicolumn{3}{c}{ Mean clo and thermal Insulation value } \\
\cline { 3 - 6 } & & \multicolumn{2}{c}{ Plain weave (1x1) } & \multicolumn{2}{c}{ Twill weave (2/2) } \\
\cline { 3 - 6 } & Blended (0:100 Oak Tasar: Acrylic) & $0.53^{\mathrm{c}}(0.06)$ & $30.9^{\mathrm{c}}(0.10)$ & $0.63^{\mathrm{b}}(0.01)$ & $42.1^{\mathrm{b}}(0.04)$ \\
\hline 1 & Union (Acrylic/ Oak Tasar) & $0.49^{\mathrm{ab}}(0.02)$ & $24.6^{\mathrm{ab}}(0.04)$ & $0.53^{\mathrm{a}}(0.00)$ & $31.2^{\mathrm{a}}(0.00)$ \\
2 & Blended (60:40 Oak Tasar: Acrylic) & $0.47^{\mathrm{a}}(0.02)$ & $21.6^{\mathrm{a}}(0.06)$ & $0.52^{\mathrm{a}}(0.04)$ & $29.4^{\mathrm{a}}(0.01)$ \\
3 & Blended (50:50 Oak Tasar: Acrylic) & $0.52^{\mathrm{bc}}(0.05)$ & $29.6^{\mathrm{bc}}(0.09)$ & $0.51^{\mathrm{a}}(0.05)$ & $28.2^{\mathrm{a}}(0.10)$ \\
4 & Blended (40:60 Oak Tasar: Acrylic) & $0.50^{\mathrm{abc}}(0.00)$ & $26.6^{\mathrm{abc}}(0.00)$ & $0.51^{\mathrm{a}}(0.01)$ & $27.7^{\mathrm{a}}(0.02)$ \\
\hline
\end{tabular}

Figures in parenthesis indicate Coefficient of variation; Different symbols ${ }^{a, a b}, b, b c c, a b c, d$ and e over the mean values indicate significant differences at $5 \%$ significance level.

Table 2. Q-max of Oak Tasar silk waste and acrylic blended woven fabrics.

\begin{tabular}{llll}
\hline \multirow{2}{*}{ S.No. } & Types of fabrics & \multicolumn{1}{c}{ Mean Q-max value $\left(\mathbf{W} / \mathrm{cm}^{2}\right)$} \\
\cline { 3 - 4 } & & Plain weave (1x1) & Twill weave (2/2) \\
\hline 1 & Blended (0:100 Oak Tasar: Acrylic) & $0.104^{\mathrm{b}}(0.023)$ & $0.103^{\mathrm{b}}(0.018)$ \\
2 & Union (Acrylic/ Oak Tasar) & $0.097^{\mathrm{a}}(0.019)$ & $0.101^{\mathrm{ab}}(0.024)$ \\
3 & Blended (60:40 Oak Tasar: Acrylic) & $0.102^{\mathrm{b}}(0.034)$ & $0.103^{\mathrm{b}}(0.029)$ \\
4 & Blended (50:50 Oak Tasar: Acrylic) & $0.100^{\mathrm{a}}(0.025)$ & $0.109^{\mathrm{c}}(0.022)$ \\
5 & Blended (40:60 Oak Tasar: Acrylic) & $0.101^{\mathrm{a}}(0.028)$ & $0.097^{\mathrm{a}}(0.012)$ \\
\hline
\end{tabular}

Figures in parenthesis indicate coefficient of variation; Different symbols ${ }^{\text {a, ab, b, c d and e }}$ over the mean values indicates significant differences at $5 \%$ significance level irrespective of different weave

pared to other blended and union plain fabrics of the plain weave. This might be due to the least $(0.30 \mathrm{~mm})$ fabric thickness of $100 \%$ acrylic plain weave fabric. Low fabric thickness compared to other blended and union fabrics resulted from the finer yarn count and lowest hairiness value of $100 \%$ acrylic yarn, which might be due to finer denier and even fibre length of acrylic fibres compared to oak Tasar fibres.

However, the union plain weave fabric exhibited lowest value $\left(0.097 \mathrm{~W} / \mathrm{cm}^{2}\right)$ of Q-max which indicated warm feeling compared to other blended plain weave fabrics. The might be because, the union fabric in which $100 \%$ oak Tasar yarn was used as weft, exhibited highest $(0.381 \mathrm{~mm})$ fabric thickness due to coarser fibre denier, yarn count as well as higher hairiness value of $100 \%$ oak Tasar yarn compared to $100 \%$ acrylic yarn.

In the case of twill weave fabrics, no such trend was observed. Inspite of higher thickness of twill weave fabrics compared to plain weave fabrics, the $Q$-max values for both types of weave were comparable. Only in case of 50:50 blend ratios, the difference between the $Q$ max values for both plain and twill weave was more.

\section{Water vapour transport rate (WVTR)}

Table 3 depicts the water vapour transport rate of developed plain and twill fabrics. It can be seen from the table that the highest WVTR in the case of plain weave was noted for $100 \%$ acrylic $\left(610.80 \mathrm{~g} / \mathrm{m}^{2} / 24 \mathrm{hr}\right)$ fabric followed by the union $\left(533.50 \mathrm{~g} / \mathrm{m}^{2} / 24 \mathrm{hr}\right), \quad 60: 40$ (507.52 g/m²/24 hr), $50: 50\left(438.60 \mathrm{~g} / \mathrm{m}^{2} / 24 \mathrm{hr}\right)$ and $40: 60$ blend $\left(437.45 \mathrm{~g} / \mathrm{m}^{2} / 24 \mathrm{hr}\right)$. There was a significant difference $(p<0.05)$ in the values of water vapour transport rate. Post hoc tukey test showed that WVTR value of $100 \%$ acrylic fabric was significantly different $(p<0.05)$ from WVTR values of $50: 50$ and 40:60 blended fabrics. No significant difference $(p>0.05)$ was found for the WVTR values of 50:50 and 40:60 blends. Similarly, WVTR values of 0:100 blend, union and 60:40 blend showed no significant difference.

In case of twill weave, the highest WVTR value was found for 40:60 (507.95 g/m²/24 hr) blended fabric followed by union $\left(497.64 \mathrm{~g} / \mathrm{m}^{2} / 24 \mathrm{hr}\right), 50: 50$ (459.75 g/ $\left.\mathrm{m}^{2} / 24 \mathrm{hr}\right), 60: 40\left(442.80 \mathrm{~g} / \mathrm{m}^{2} / 24 \mathrm{hr}\right)$ and $0: 100$ blend (451.34 g/m²/24 hr). Statistically, WTVR value for twill weave fabrics of all blend ratios had no significant difference at $5 \%$ significance level.

The high value of water vapour transport rate for $100 \%$ acrylic fabric can be explained by the low fabric cover of $100 \%$ acrylic plain weave fabric. Due to the finer yarn count of $100 \%$ acrylic yarn and less warp per inch, it had low fabric cover compared to other blended plain weave fabrics. The low cover factor resulted in an in- 
crease in open space in the fabric which increased the water vapour diffusivity of the $100 \%$ acrylic plain weave fabric. Das and Kothari (2012) observed that fabric porosity of fabric decreased as fabric cover increases which further increased the water vapour resistance. It was also reported that fabrics with higher yarn count showed higher water vapour permeability. However, in the case of union fabric, 60:40, 50:50 and 40:60 blended plain weave fabrics, water vapour permeability was increased with increasing oak Tasar silk fibre content in the blend. This behaviour can be explained by the high moisture regain of the oak Tasar silk fibre. Mortan and Hearle (2008) reported that water vapour diffusivity of the material increases with moisture regaining. In the present study, as the oak Tasar proportion in the fabric was increased, the moisture regain of the material would have increased, causing higher diffusivity. The union fabric exhibited a higher water vapour permeability value than 60:40, 50:50 and 40:60 blended fabrics. In the case of twill weave fabrics no such trend was observed. The values of water vapour permeability for twill weave showed no significant difference at $5 \%$ significant level.

\section{Air permeability}

The data pertaining to air permeability of both plain and twill weave fabrics are given in Table 4 . The highest air permeability among plain weave fabrics was found in
$100 \%$ acrylic fabric $\left(0.19 \mathrm{~m}^{3} / \mathrm{m}^{2} / \mathrm{min}\right)$ followed by $40: 60$ (0.17 $\left.\mathrm{m}^{3} / \mathrm{m}^{2} / \mathrm{min}\right), 50: 50\left(0.16 \mathrm{~m}^{3} / \mathrm{m}^{2} / \mathrm{min}\right), 60: 40(0.15$ $\left.\mathrm{m}^{3} / \mathrm{m}^{2} / \mathrm{min}\right)$ and acrylic/Tasar union fabric $\left(0.12 \mathrm{~m}^{3} / \mathrm{m}^{2} /\right.$ $\mathrm{min})$. The ANOVA depicted that there was a significant difference $(p<0.05)$ among the air permeability values of plain weave fabrics of different blend ratios. Tukey post hoc test showed that air permeability values of 40:60 and 50:50 blend ratios were at par to each other at $5 \%$ significant level. However, air permeability values of $0: 100$, union, $60: 40$ and 50:50 had significant difference $(p<0.05)$ with each other.

In the case of twill weave, the highest value of air permeability was obtained for $100 \%$ acrylic fabric $\left(0.12 \mathrm{~m}^{3} /\right.$ $\mathrm{m}^{2} / \mathrm{min}$ ) and least for acrylic/Tasar union fabric (0.06 $\left.\mathrm{m}^{3} / \mathrm{m}^{2} / \mathrm{min}\right)$. Air permeability values of $60: 40,50: 50$ and $40: 60$ blends were $0.08 \mathrm{~m}^{3} / \mathrm{m}^{2} / \mathrm{min}, 0.07 \mathrm{~m}^{3} / \mathrm{m}^{2} / \mathrm{min}$ and $0.11 \mathrm{~m}^{3} / \mathrm{m}^{2} / \mathrm{min}$ respectively. Statistically, it was found that air permeability values of $0: 100$, union, $60: 40$ and $40: 60$ were significantly different from each other at $5 \%$ level of significance. However, air permeability values of $60: 40$ and $50: 50$ blends were at par $(p<0.05)$. Similarly, values of 50:50 and union fabric were at par with each other $(p<0.05)$.

It can be observed from the data that in the case of plain weave fabrics, air permeability values increased with an increase in acrylic fibre content in the blend. The union fabric exhibited the lowest air permeability value. This might be because of finer yarn count and

Table 3. Water vapour transport rate of Oak Tasar silk waste and acrylic blended woven fabrics.

\begin{tabular}{|c|c|c|c|}
\hline \multirow{2}{*}{ S. No. } & \multirow{2}{*}{ Types of fabrics } & \multicolumn{2}{|c|}{ Mean water vapour transport rate ( $\mathrm{g} / \mathrm{m}^{2} / 24$ hours) } \\
\hline & & Plain weave $(1 \times 1)$ & Twill weave $(2 / 2)$ \\
\hline 1 & Blended (0:100 Oak Tasar: Acrylic) & $610.80^{\mathrm{b}}(0.30)$ & $451.34^{a}(0.07)$ \\
\hline 2 & Union (Acrylic/ Oak Tasar) & $533.50^{\mathrm{ab}}(0.70)$ & $497.64^{a}(0.01)$ \\
\hline 3 & Blended (60:40 Oak Tasar: Acrylic) & $507.52^{\mathrm{ab}}(0.00)$ & $442.80^{\mathrm{a}}(0.07)$ \\
\hline 4 & Blended (50:50 Oak Tasar: Acrylic) & $438.60^{a}(0.08)$ & $459.75^{\mathrm{a}}(0.15)$ \\
\hline 5 & Blended (40:60 Oak Tasar: Acrylic) & $437.45^{\mathrm{a}}(0.08)$ & $507.95^{\mathrm{a}}(0.04)$ \\
\hline
\end{tabular}

Figures in parenthesis indicate coefficient of variation.

Different symbols ${ }^{a, a b, b, c, d \text { and } e}$ over the mean values indicates significant differences at $5 \%$ significance level irrespective of weaves.

Table 4. Air permeability of woven fabrics.

\begin{tabular}{llll}
\hline \multirow{2}{*}{ S.No. } & Types of fabrics & \multicolumn{2}{c}{ Mean air permeability $\left(\mathbf{m}^{3} / \mathrm{m}^{2} / \mathrm{min}^{2}\right)$} \\
\cline { 3 - 4 } & & Plain weave (1x1) & Twill weave (2/2) \\
\hline 1 & Blended (0:100 Oak Tasar: Acrylic) & $0.19^{\mathrm{d}}(0.03)$ & $0.12^{\mathrm{c}}(0.01)$ \\
2 & Union (Acrylic/ Oak Tasar) & $0.12^{\mathrm{a}}(0.05)$ & $0.06^{\mathrm{a}}(0.11)$ \\
3 & Blended (60:40 Oak Tasar: Acrylic) & $0.15^{\mathrm{b}}(0.05)$ & $0.08^{\mathrm{b}}(0.16)$ \\
4 & Blended (50:50 Oak Tasar: Acrylic) & $0.16^{\mathrm{c}}(0.01)$ & $0.07^{\mathrm{ab}}(0.85)$ \\
5 & Blended (40:60 Oak Tasar: Acrylic) & $0.17^{\mathrm{c}}(0.03)$ & $0.11^{\mathrm{c}}(0.05)$ \\
\hline
\end{tabular}

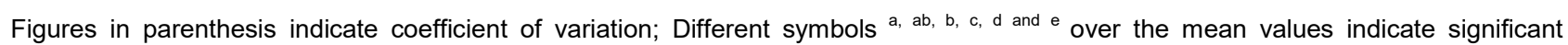
differences at $5 \%$ significance level irrespective of different weaves. 
low value of hairiness of $100 \%$ acrylic yarn and 40:60 blended yarn compared to $60: 40$ and 50:50 blended yarns. The finer yarn count resulted in a lower cloth cover of those fabrics, which contributed to a more porous structure to $100 \%$ acrylic and $40: 60$ blended fabrics. Therefore more air would have passed through a more porous structure. In the case of union fabric, 100 $\%$ oak Tasar silk yarn was used as a weft. The union fabric had higher fabric thickness and cover factor compared to other blended fabrics. This was due to higher hairiness value and coarser yarn count of $100 \%$ oak Tasar yarn compared to $100 \%$ acrylic and $40: 60$ blended yarn. A similar trend was observed for the twill weave fabrics. Thus less porous structure compared to $100 \%$ acrylic and 40:60 blended fabric, which allowed less air to pass. On comparing air permeability values of plain weave and twill weave, it was observed that plain weave fabrics had higher air permeability as compared to twill weave fabrics for all blended and union fabrics.

Tastan et al. (2017) investigated the effect of structural parameters of cotton woven fabric on their air permeability. In their study, they reported that air permeability of fabrics largely depended upon the fabric construction, notably density, porosity and thickness. They observed that coarser yarn reduced the air permeability. The weave structure with long floats exhibited high air permeability and weaves with a high number of interlacements had low air permeability. The plain weave had dense and firm as compared to $1 / 3$ and $1 / 7$ sateen, which resist air passage through the fabric structure. But in the present study, plain weave fabric showed more air passage compared to twill weave. This might be due to the higher thread count of twill weave fabrics than plain weave fabrics, which resulted in dense fabric with more cloth cover than plain weave fabrics.

\section{Conclusion}

The study concluded that the air permeability of plain weave fabrics was more compared to twill weave fabrics among the developed fabrics. Thermal insulation and clo value were increased with increasing acrylic content in the fabric. In contrast, Q- max, air permeability, water vapour permeability values were reduced with the addition of oak Tasar silk fiber in the blend. Most of the comfort properties of different blended and union fabrics were more or less close to each other for both plain and twill weaves. It is recommended that developed blended and union fabrics may be used for light winter wear clothing and apparels as the developed fabrics were light in weight and had clo values comparable to a sweater. The developed yarns and fabrics extended the end-use of oak Tasar silk waste, facilitating the diversified product range in apparels through finer yarns and fabrics.

\section{Conflict of interest}

The authors declare that they have no conflict of interest.

\section{REFERENCES}

1. Anonymous (2010). Thermal comfort of fabrics. Retrieved on 20,April, 2021 from http://shodhganga.inflibnet.ac.in/ bitstream/10603/74043/16/16_chapter \%2 09.pdf

2. Chattopadhyay, R. (2008). Design of apparel fabrics: role of fibre, yarn and fabric parameters on its functional attributes. Journal of Textile Engineering,. 54(6), 179-190.

3. Das, B., Das, A., Kothari, V. K., Fanguiero, R. \&and Araujo, M. D. (2009). Moisture flow through blended fabrics-effect of hydrophilicity. Indian Journal of Fibre and Textile Research, 4(4), 20-28.

4. Das, S. \& Kothari, V.K. (2012). Moisture vapour transmission behaviour of cotton fabrics. Indian Journal of Fibre and Textile Research, 37 (6),151-156.

5. Ghosh, S. K., Bairagi, S., Dutta, S. \& Bhattacharyya, R. (2016). A comparative study of the thermal insulation properties of jute and jute polyester fibre blended nonwoven fabrics. American Journal of Engineering Research, 5 (8),: 43-49.

6. Morton, W.E. \& Hearle J.W.S., (2008). Physical properties of textile fibres. $4^{\text {th }}$ edition, Woodhead Publishing Limited, Cambridge, England, pp-765.

7. Raeve, A. D., Vasile S \& Cools, J. (2018). Selected factors influencing wear comfort of clothing: case studies. $J$ Textile Eng Fashion Technology, 4(1), 66-71. DOI: 10.15406/jteft.2018.04.00123

8. Saville, B.P. (2004). Physical testing of textiles. Cambridge, Woodhead Publishing Limited. 310p.

9. Shekar, R.I., Kasturiya, N., Raj, H. \& Nigam, S. (2001). Influence of wool- synthetic fibre blends on thermal insulation. Indian Journal of Fibre and Textile Research, 26(8), 287-295.

10. Song, G. (2011). Improving comfort in clothing. Cambridge, Woodhead Publishing. 496p.

11. Tastan, E., Akgun, M., Gurarda, A . \& Omeroglu, S. (2017). Investigation of the effect of different structural parameters of cotton woven fabrics on their air permeability. Bristol, IOP Publishing Ltd. 254p.

12. Valsang, R. K. \& Patil, L. G. (2013). Thermal comfort in clothing: a review. The Indian Textile Journal, retrieved on 14 April 2021 from https://indiantextilejournal.com/articles/ FAdetails.asp?id=5523\#: :text=Human $\% 20$ thermal\% 20 comfort $\% 20$ depends $\% 20$ on, reduces $\% 20$ the $\%$ 20body's\%20heat\%20loss.

13. Narkhedkar R.N. \& Vora P.S. (2017) Cold Protection: A need for cold region body wearers. Fibre to fashion.com Retreived on 14 April 2021 from https:// www.researchgate.net/profile/Pranil-Vora/publication/313 479424_Cold_Protection_A_need_for_cold_region_ body_wearers/links/589c66e8a6fdcc $7 \overline{5} 4178 \bar{b} 80 \mathrm{a} / \mathrm{Cold}$ Protection-A-need-for-cold-region-body-wearers.pdf 